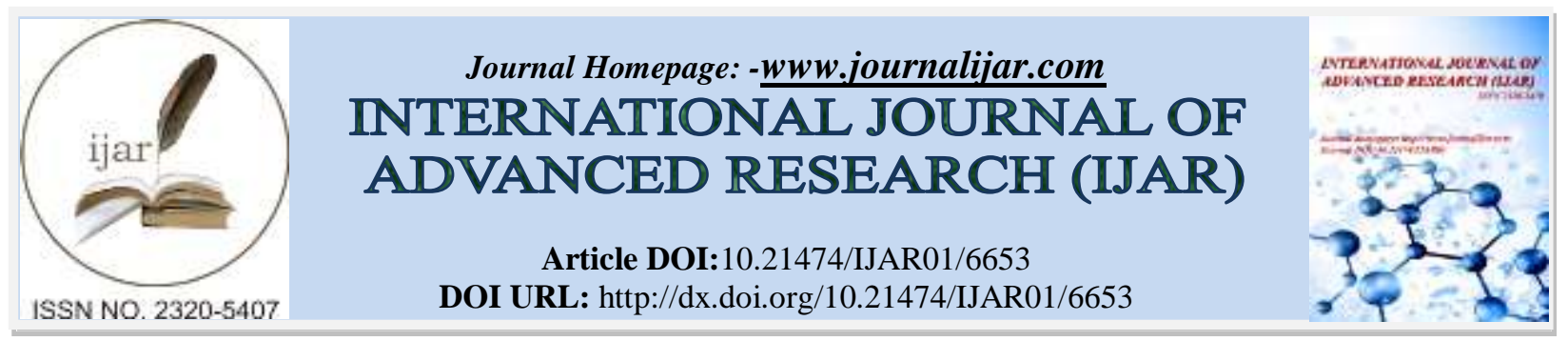

RESEARCH ARTICLE

\title{
THE EFFECT OF CONSTRUCTIVE PLAY WITH CLAY MEDIA TOWARDS FINE MOTOR SKILL OF CHILDREN
}

\author{
Nirwana, Laila Maharani and Miftahul Jannah. \\ Stkip Kusuma Negara Jakarta
}

\section{Manuscript Info}

Manuscript History

Received: 03 January 2018

Final Accepted: 05 February 2018

Published: March 2018

Keywords:-

Constructive, Fine Motor Skills, Clay.

\begin{abstract}
The objective of this research is to increase the fine motor skills of children. The method used in the learning process is more likely using conventional methods. The use of constructive play method with clay media in this research is expected to make children motivated and interested to learn and can stimulate their. Therefore, this study aims to fine out the description of fine motor skill of children which was given a treatment in the form of constructive play method implementation with clay media towards children fine motor skills. The type of research used is Quasi Experiment. The population in this study were all of 11 children for experimental group and group 11 children for control group. The data collection techniques used are test observation techniques. The data analysis techniques used are statistical descriptive and nonparametric statistical analysis. Based on Wilcoxon test results, as shown in the attachment, obtained arithmatic $=66$ with price of $\mathrm{t}_{-}(\mathrm{table}=) 11$ and $\mathrm{dk}=11$ level and significance level is 0.05 . So if compared the value of $t \_$count $=66>$ the value of $t_{-}$(table $\left.=\right) 11$. This data shows a significant difference between the two groups tested.
\end{abstract}

Copy Right, IJAR, 2018,. All rights reserved.

\section{Introduction:-}

Fine motor skill as a movement that requires control of small sized muscles to achieve certain goals that include hand-eye coordination and movement that requires fingers and can be used in doing the work or manipulating objects. The fine motor skill can improve well if it gets the right stimulation from an early age. As the results of Haris and Selmir's research "Development Of Fine Motor Coordination and Visual-Motor Integration In Preschool Children". The study was conducted on preschoolers consisting of 276 children in Canton Sarajevo. Using one-way Anova analysis data was continued by comparison between age groups. The results of this study indicate that age has a great influence on the fine motor development of children. Provision of early intervention is needed so that in the future children have readiness that can affect their ability to read and write.

The research results conducted by Michelle Huffman and Callie Fortenberry "Developing Fine Motor Skill" in his article stated that fine motor skill is a comprehensive process that starts from the arm movements to the fingers. Various activities can be done in an effort to develop fine motor skill of a child involving the whole arm and hand by drawing, playing with buttons and pinning. 
The research undertaken by Suzanne entitled "Factoring in Fine Motor How Improving Fine Motor Abilities Impacts Reading and Writing" reveals that fine motor skill as a factor to determine whether a child is ready for school and assessing their literacy skills. It also explores the role of teachers in the acquisition of fine motor skill.

Furthermore, a research from Sargent, Marianne entitled "Within grasp" discusses different methods and products that can be used to help preschool children to develop fine motor skill and physical skill control that include carpentry games, weavers, and puzzles. In this research media is used to develop fine motor abilities of children.

In addition, one of the activities to stimulate fine motor of preschool children is constructive play activity. When children play contructively, they are actively involved. "Constructive play using objects or materials (sand, playdoh, paint) to make something. The children may practice out playdough like pie dough. This is object concept development, small motor development."

Constructive play is an activity that uses a variety of materials that exist to create a particular work. As stated by Stone above - for example - playing using objects to create something from the beam, clay, and so forth. The results of research conducted by Walter, James, Alice and Nell revealed that in constructive play various media can be used like beams and clay to build objects.

This is confirmed by Englebright and Robert: "working with clay fosters large muscle and fine motor control. Hard clay provides solid resistance of the child must overcome. This will involve using in the shoulders, arms, hands, and fingers."

Clay is a kind of loam that is good for children to make a variety of toys. In the past clay is still limited basic materials and must be willing to merge with the soil to get a quality clay, because to produce good and beautiful work of course must have a quality basic ingredients. As the times progressed, people now think more and more. To make clay crafts do not have to be from pure soil, but can be replaced with the basic ingredients of flour. Clay needs squeezing to make it soft.

Clay is thought to be able to develop fine motor control by using the fingers to perform various hand activities, such as squeezing, shaping, cutting with a plastic knife, rolling and printing, folding, stringing, sticking, and composing.

Research by Rogers, Liz Steffan, Dana, entitled "Clay Play", shows that clay has the potential to be a learning tool for children. Clay has a soft and flexible texture for imagination. Playing clay makes your child's hand muscles strong.

Based on the above explanation, the researcher is interested to examine more deeply about the effectiveness of clay media in Kindergarten in group B, so the researcher took the title "The Effect of Constructive Play Method with Clay Media towards Fine Motor Skill of Children In Group B In Aisyiyah Bustanul Kindergarten Athfal V Ranting Toddopuli Perumnas Tello Baru Makassar."

\section{Fine Motor:-}

fine motor skill is associated with smoother movements using fingers like toy, using spoons, buttoning, or anything that demands the ability of a finger to demonstrate fine motor skill.

Gross motor skills involve large-muscle activity, fine motor skills involve finely tuned movement. Grasping a toy, using spoon, buttoning a shirt, or doing anything that requires finger dexterity demonstrate fine motor skills. Fine motor skills requaire greater control of the small muscles, especially those involved in hand-eye coordination, and require a high degree of precision in hand and finger movement.

Fine motor skill as an ability that requires strong control of smooth muscles with a high degree of precision as revealed by Magill above. When children are able to perform a motor movement, then they will be motivated to move to a more extensive motor that allows the movement of muscles more leverage. So it takes the children to respond smooth movements through their small muscles. This is very important in accelerating the progress of learning fine motor skill. Furthermore expressed by Cheryl: 
Fine motor skill a motor skill involving very precise movements normally accomplishied using smaller musculture. Fine motor skil control is needed to manipulate, fine motor kontrol has a significant impact on the extent to which many skills can be performed proficiency, accordingly, the degree of fine motor control display during the performance of a skill can be used to assess skill development.

From Cheryl's opinion it is understood that fine motor control is required to manipulate objects, fine motor has influence also on other aspects such as enhancing the ability of skill, besides the level of fine motor control shown in an ability can be used to assess the development of other abilities.

Similarly, Penney Upton suggests that fine motor skill involves small muscles that allow functions such as grasping and manipulating small objects, which involves power, fine motor control and deftness. Suyadi revealed that fine motor movement is the increasing coordination of gestures involving muscle groups and other small nerves. Meanwhile, according to Janet W. Lerner, fine motor movement is the ability to use the media with the coordination between the eyes and hands. Anne V Gormly and David M stated that "fine motor skills control of the small muscles and finger movement".

Fine motor skill is also interpreted by Martorel, Papalia and Feldman: Fine motor skill is physical skills that involve the small mucles and eye-hand coordination". Fine motoric as an ability that requires strong control of the muscles especially those included in eye-hand coordination. Such as using scissors, pencils, and chop sticks all improve markedly during early childhood.

Therefore, fine motor movement does not require much energy, but requires careful coordination, agility and accuracy. Fine motor skill begins to develop, having begun very simple activities such as holding pencils, knives, holding spoons, and stirring. Fine motor skill last longer because they require more difficult skills such as concentration, control, prudence and coordination of one's muscles with another. Along with the age of the children, their intelligence of fine motor skills is growing.

Various activities that can be done by children in using their finger muscles as revealed by Gallahue and Ozmun: Gallahue and Ozmun fine motor skills use several small muscles to perform a movement task with precision (writing, typing, kinitting, portrait, painting).

The fine motor skill exposed by Gallahue and Ozmon in the form of fine motor that uses small muscles to perform movements with precision such as writing, typing, knitting, photographing and painting. Precision requires quick and precise movement of hands and fingers. Fine motor skill that can develop eye-hand coordination of children is to play the dough. Children use hands and equipment to pound, squeeze, shape, flatten, roll, cut and break the dough. It also helps children in coordinating their hands and eyes.

Hand-eye coordination is the ability to use the hand appropriately to control the child's object. For example, when processing the shape, the eye will always follow the movement of the fingers when directing the shape to assembled well. Eye coordination has two aspects: self-help aspects such as washing hands, combing hair, wearing clothes, and learning skills such as cutting, folding, playing play-doh, peeling, designing, or coloring drawings require hand-tohand coordination and eyes. It is also presented by Papalia, Feldman and Gabriel:

Fine motor skils is physical skills that involve the small mucles and eye-hand coordinatioan. Such as buttoning shirts and drawing picture, involve eye-hand and small-muscle coordination. Gains in these skils allow young children to make more responsibility for their personal care.

The fine motor abilities described above are various such as grasping, holding, tearing, cutting. For hand-eye coordination consists of activities in the form of grasping, dipping, sewing, folding, cutting, drawing, coloring, playdough play. Motor activities can be done with various activities and media that can support the success of stimulation.

Furthermore Feldman and Gabriel stated that, "Fine motor skills precise movements of particular parts of the body, especilly the hands. Such as drawing, writing, cutting with scissors, and manipulating small objects". 
The fine motor skill stated by Feldman and Gabriel is the ability that involve small muscles and the eyes-hands. Such as buttoning clothes and drawing that requires the coordination of the hands and small muscles. The purpose of this ability allows the students to be responsible for themselves.

The fine motor skill presented by the experts above are very helpful for the children in coordinating their eyes and hands, but it also can stimulate the flexibility and agility of children. The muscles of a trained children will get used to doing things without a hitch such as children being able to attach his own shoelace without the help of others, they can pick up small objects, they can manipulate small objects during play.

These capabilities are needed by the children because the finger grip becomes the basis for children's manual abilities such as writing, drawing, using scissors, wearing buttons and so on.

Basically any activity done by early childhood involves eye-hand coordination. The more movement done by the children the more coordination it needs. Therefore children need activities that support their fine motor which certainly designed well in accordance with the age of their development. The development of fine motor involves the smooth muscles that control the hands associated with childhood is greatly emphasized on the control in manipulating objects, eye-hand coordination and accuracy in the use of hands and fingers.

Based on the above opinions it can be concluded that fine motor skills are movements that involve specific body parts especially the fingers that are included in aspects of manipulation, precision, and hand-eye coordination.

Constructive play is the activity of children that uses various tools and certain objects. Through constructive play activities the children will have the opportunity to think imaginatively so that their mind become more empowered. Thus constructive play activities also contribute to the development of preschool children's creativity.

According to Judith etc,

Constructive play provides a natural link between practice or functional play and more sophisticated forms of symbolic play. In consctructive play the child uses conrete objects to create a representasion of an object ; bloks or playdough manipulated to represent a house are typical examples.

From the above opinion it can be concluded that constructive play is a constructive way of playing, fostering, improving, where children will use materials to make something that is not intended to be useful, but for the joy it derives from making it. For example manipulating the form of playdough.

Subsequently Piaget reveals that constructive play involves manipulating physical objects to construct something. For example by playing clay, children can form anything that they want, for example making triangles, circles, boxes or rectangles. In playing children actively involve themselves. They engage in a creation or design a product or a problem solving of their own creation. Children play by using materials to make things that are not only for beneficial purposes but also for the joys it derives from making them. Through play activities using this material, the child develops the ability to be creative.

Stone quotes Rubin Fein Vanderberg as saying that constructive play is a combination of sensorimotor play and symbolic play. Constructive play is very beneficial for children, because it is able to stimulate children's creativity and develop social skill if it is conducted with other friends. Constructive play by manipulating objects contributes to the children's understanding of an object and an appreciation of changes and circumstances of time and space.

According to Rubin, Fein \& Vanderbenberg, constructive play can already be seen in children aged 3-6 years. In this playing activity the children form something, creating a certain building with the available game tools. For example, making a home-based house with wooden blocks or pieces of lego, drawing, arranging pieces of pictures and the like.

Constructive play has the purpose of stimulating creativity as well as children's imagination. The children must imagine the shape to be made, the taste of art needed so that the results look beautiful. Fine motor skills will also be felt through the activities of this play, as well as diligence and concentration. This was stated by Stone: 
Constructive play combines the sensory and motor functional play with symbolic play. in constuctive play, a child begins using intellectual processes in play. She must recognize and retrieve previously stored information (memory), she must create in her mind and then construct in reality, she is the engginer with bloks, the artist with paint, the sculptor with clay, and the designer with "junk""constructive play using objects or materials ( sand,playdoh, paint) to make something." The children may practice out playdough like pie dough. This is object concept development, small motor development.

Constructive play combines motor functional and sensory games with symbolic games. In a constructive game, according to Stone, the children begin to use the intellectual process in playing. They are able to know or inform the previously stored in their memories. The children must create in their mind and then build it in reality. They build with blocks, decorate with color, and sculpt with clay, and design with recycling. Constructive games use objects or materials to make things. Children can practice play-doh like a pie. This activity is able to develop their fine motor skills. Constructive play presumes possession of all the aforementioned motor and sensory.

There are two types of constructive play materials according to Wolfgang: (1) constructive play with liquid materials, such as paint, crayons, markers, clay, water. These materials mostly trains sensorimotor; (2) constructive play with constructed materials, meaning that the material has been formed that directs how the children put the materials into a work such as lego, puzzles, beams.

In constructive play the children are able to take a decision on their own to choose, define, create, install, disassemble, restore, try and express opinions, work diligently, cooperate with friends and experience various feelings. Furthermore, according to Mayke, activities included in constructive play are drawing, creating certain shapes of toy candles, cutting, sticking paper or cloth, assembling pieces of wood or plastic into a particular shape.

Based on the above opinion can be understood that constructive play is an activity in manipulating objects to create or build something, one of them is by using clay.

Clay:-

One type of crafts is by using clay. In Indonesia the word clay becomes a popular word and is usually synonymous with a unique craft, because the material can be formed into various creations with various functions. Crafting using clay is very easy to learn from children to adults.

Everyone loves beautiful ornaments. Especially when the decoration is made by hand alone. Clay is a medium that can be used as a basic material in making crafts. In the past clay is still limited basic materials and it merged with the ground to get a quality clay because to produce good and beautiful work of course must have a quality basic ingredients.

As the times progressed, people now also thought forward. To make clay crafts do not have to be from material from ground, but can be from the basic ingredients of flour.

Clay is a good material used by children to make a variety of toys. There are several benefits children play clay according to Dorothy Clay is particularly good for taking impressions but you could also salt dough. Rool the dough into smooth round balls-about the size of a golf ball. Press them againts hard rough surfaces such as walls, trees, shoe treads or the patterned ends of cutlery. The patterns can then be dried. You coulsd also roll out the dough and press varoius objects into it to make patterns.

The benefits of playing clay make the children impressed. When children play clay they can choose what they want to make. By playing clay they can learn that a soft object can harden when it has been applied. They are also able to understand the three-dimensional work. The children have experience about the various clays they can use to enhance their creativity. For same children the clay is used to outline forms, with snake-like shapes being substituted for drawn lines; these are arranged on a flat surface so that the finished product appears in relief rather than as a free-standing piece of sculpture.

Clay is one of the media that can stimulate fine motor. As stated by Jill Englebright and Robert: 
Working with clay fosters large muscle and fine motor control. Clay is fairly resistant and will need to be kneade and worked to make it pliable. Children can stand or sit while using clay. Standing provides the advantage of awhole-body muscular reaction to the clay. Hard clay provides solid resistance the child must overcome. This will involve using in the shoulders, arms, hands, and fingers if the child seated.

Playing with clay develops large muscles and fine motor control because the clay is quite resistant and kneaded to make it soft. Children can sit or stand while using clay. By standing affects the whole body muscle reaction to the clay. They will use shoulder arm muscles and fingers. Meanwhile, if children sit, indirectly children control the media and make things as desired.

The children enjoy playing clay for several reasons. Clay is a natural material that is just as interesting when they play sand, water and wood. From the clay art aspect they can change or modify what they have created. For example a snowman can be converted into pizza. It is different when they use crayon that can not be changed again. In addition, children easily control the clay media.

Playing with clay is a multisensory experience. Clay has a different texture, temperature, color and smell. The benefits of playing clay is one of the activities that can provide them with home study opportunities, clay recipes, sizes and mixes. Children enjoy playing clay and allowing them to play dirty and untidy so this activity indirectly teaches children to be able to explore so that children are very interested to play it.

Clay has a therapeutic effect on introverted children. Because by playing clay the children are able to vent the aggression on the clay, for example a child who is disillusioned with his parents' divorce who is unable to express his feelings verbally, clay gives him a solution to express his feelings by playing dramas with a miniature family of clay. This is expressed by Jill Englebright Clay has a therapeutic effect. It allows the working through of emotions and creating of model sitaution. A child who is upset by a recent divorce may be unable to expres how he or she fells verbally. Clay, however, provides this child with the opportunity to work through his or her feelings by talking to and dramatizing with a family made out of clay.

Furthermore, in a study conducted by Rosalie Rebollo he said: " Clay has been used as a therapeutic tool in patiens who have sustained ceveral vascular accidents and femur neck fracture to combine sensorimotor activities of the upper limbs with sosial interaction.

Clay needs to be squeezed to make it soft. Clay should be stored in a sealed container. Playing clay for children is fun, because they can manipulate it as they like, its soft texture makes clay very easy to shape and appeals to children. This is also expressed by Brewer PPreschoolers spend most of their play time in exploratory or practice play. They are focused on the process, their than the product, of their play. For example, they might mix the colors of paint or the colors of clay, but their interest is in what happens to the materials, not in the painting or sculpute that later results.

Playing clay has the goal of improving the ability to think creatively and to train originality in the work. Playing clay is giving the children the opportunity to perform activities in exercising smooth muscles and fingers. Besides playing clay can help children develop the ability of creativity and artistic. Playing clay can be an interesting art activity that can even develop math and literacy.

Play dough and clay wonderful materials to help kindergarten children develop their creativity and artistic skills. Making play dough with a small group of children can be a fun art also activity, but can also integrate mathematic and literacy". Kristin was one of the teachers who had made an observation concluding that:

" ....they literally used their whole bodies to press into it. They stood on chairs to get more leverage. They puhed and squeezed and pounded with all their might. They use hand, fingers, fists, chests, foreheads, and elbows to flatten and shape the dough"

When playing clay various activities can be done such as rolling and cutting. Children can use objects to scroll clay and then print according to the desired shape. As Jasqueline did: used the clay lines in a different way to represent her family. Playing clay makes children socially involved. They can play with their friends when making toys from clay. 
This is expressed by Fergus P. Hughes: Psychologistr Ruth Hartley spoke of the "almost magical touge-loosening quality of clay". By this she meant that even the most inhibited of children will often socialized freely when they play with clay. Thus clay can serve as a protective shield behind which children can hide and study their peer group until they are ready to enter the group on their own terms.

Jill and Robert reveal a variety of activities that can be done with clay:

Some ways to process with clay include

1. Fingering and squeezing the clay

2. Rolling clay into round balls, coiling, streching, and lengthening, squashing, or pounding clay into a pancake, pinching off pieces of clay, cutting the clay with blunt scissors, poking holes or openings into clay, tearing or pulling apart as well as joining pieces of clay.

3. Stamping or imprinting the clay twisting or braiding lengths of clay.

4. Forming or molding clay into nest or bowls, squeezing or sculpting clay into a solid three-dimensional, seltstanding form, cutting into clay with aplastic knife.

5. Procesing with clay and a variety of clay tools and accessories

6. Folding or bending clay.

From this opinion it can be understood that playing with clay develops fine motor control by using the fingers to perform various hand activities, such as squeezing clay, shaping, cutting with a plastic knife, grasping, rolling and printing, folding, stringing, sticking, and arranging.

\section{Research Method:-}

The research method used for this research is Quasi-Experimental research. This method has a control group, but it is not fully functional to control the outside variables that affect the experiment. This quasi-experimental method is used to determine the smooth motor development of children who are treated constructively with clay media and play constructively with conventional methods. The use of this type of research is based on the nature of the population, ie. students who are not fixed and varied.

\section{Result and Discussion:-}

Based on the Wilcoxon test results there is a significant difference between the fine motor skill of children who participate in the learning activity with constructive play method that use clay media with groups of children who participate in the learning with conventional method.

In this case, the average of fine motor skill score for the group of children following the learning with constructive play method using clay media is higher than the average score of fine motor skill for the group of children following the conventional method.

This is because the method of constructive play with clay media involves the children directly in every activity in using their fingers so that their fine motor is trained better. Clay has several benefits for children as suggested by Indira (2016), such as developing fine motor skills, recognizing color concepts, broadening insights and knowledge. Meanwhile, according to Dorothy (1999), by playing clay children will understand the concept of three dimensions, the children have direct experience how to use their fingers in play. Clay is one of the media that can stimulate fine motor. As revealed by Englebright and Robert (2012), playing with clay can grow large muscles and fine motor control. When children play clay will involve the shoulder muscles, arms, hands, and fingers of children when playing it. encourage self-confidence and generate pride in achieving it.

There are some fine motor activities with constructive play method with clay media, such as clay dough printing activity, forming clay shape, sticking clay shape, making collage from clay, and designing clay shape, where in each activity the children performs on his own with the directions and examples described by the previous teacher.

In clay dough printing activities, children appear to use the fingers and palms of the hands when they shake the clay flat and then print the shape with a little pressure on the palm of the hand. Children with good motor skills will produce good and neat clay prints. After the children print the clay it will be taped to a plastic glass to be used as a stationery place. 
In the clay-making activity, many children involve the tips of their fingers when making a shape, especially a cone shape or a drop of water to be formed into a star shape. In addition also when the children stick the shape of stars using clay, the children try to be able to attach properly to produce the work of stars from the beautiful clay. Children who can not stick to the exact shape can be said to have a less interesting work.

For clay-making activities, children need aspects of precision when arranging forms on collage patterns provided by the teacher. From the results of the study it is found that when children make collages they organize various forms such as round, oval, conical, in their place so that children's work illustrates good results and it is understandable that the children created a collage on the star shape, in accordance with the theme of learning.

In the activity of forming clay, children also need concentration to coordinate their eyes and hands when stringing various forms that they have made by themselves into sunflower shape. In this activity the children seem not too difficult because this activity is most last done. Children are accustomed to being trained in their previous activities.

While fine motor activities on learning with conventional methods, which are still teacher-centered learning methods, the lack of active involvement of students during the learning process leads the children to be confused about what to do during the activity. The lack of learning facilities and infrastructure in which children are only equipped with worksheets in every learning automatically makes them bored so that the children creativity less satisfactory, as evidenced by the number of scratches during coloring, unkempt children's writing and the independency in their works has not seen and lack of creativity of teachers in choosing methods and media in activities that are able to develop fine motor skills of children.

Thus it can be concluded that there are some things that cause differences in the score of fine motor skills of children between a group who participates in the learning activities with constructive play method using clay media and a group who learns with conventional method, where the score of fine motor skills of children who follow the learning with constructive play method that uses clay media is higher than the group of children that follows the conventional learning activities.

\section{Conclusion and Suggestion:-}

Based on the results of analysis and statistical tests in the previous discussion, it can be concluded as follows:

1. The results of fine motor skills for group of children who participate in the learning with constructive play method with clay media included in the high category.

2. The results of fine motor skills for group of children participate in the conventional learning process in the medium category.

3. There is an effective effect in the application of constructive play method with clay media to the fine motor skills of children.

\section{Reference:-}

1. Coker, Cheryl A. 2014. Motor Learning and Control For Practitioners. America: McGraw-Hill.

2. Einon's, Dorothy. 1999. Learning Early. London: Marshall Publishing.

3. Englebringt, Jill \& Robert. 2012. Art \& Creative Development for Young Children. 7th Edition. Unites State of America : Wadsworth.

4. Fergus. P. Hughes. 2010. Children, Play, and Development. 4th Edition. Unites State of America: Sage Publication.

5. Gallahu, Davhi L \& Joh C. Ozmun. 2006. Undertanding Motor Development Infants, Children, Adolescents, Adults, Sixth Edition. Singapore: Internasional Edition.

6. Gormly, Anne V \& David M. Brodzinsky. 2010. lifespan Human Development. Fifth Edition. New York: Harcourt Brace Javanoviich Colleg.

7. Indira. Yuk Berkreasi dengan Adonan Clay. Jakarta: Gramedia Putaka Utama. 2009.

8. Tedjasaputra S. Mayke. 2007. Bermain, Maindan dan Permainan. Jakarta: PT Grasindo.

9. Judith, Patricia, Barbara \& Keith. 1993. Play at the Center of the Curriculum, 4th Edition. Unites State of America : Pearson Education.

10. Papalia \& Gabriel. 2.000. Experience Human Development, Thirteenth Edition Edition. United State Of Amerika: McGraw-Hill.

11. Stone, Sandra J. 1993. Playing A Kids Curriculum. United States of America: Harper Collins. 